FEDERAL

RESERVE

BANK of

ST. LOUIS

\section{RESEARCH DIVISION} Working Paper Series

\title{
Intergenerational Policy and the Measurement of Tax Incidence
}

\author{
Juan Carlos Conesa \\ and \\ Carlos Garriga
}

Working Paper 2013-016B

https://doi.org/10.20955/wp.2013.016

October 2015

\author{
FEDERAL RESERVE BANK OF ST. LOUIS \\ Research Division \\ P.O. Box 442 \\ St. Louis, MO 63166
}

The views expressed are those of the individual authors and do not necessarily reflect official positions of the Federal Reserve Bank of St. Louis, the Federal Reserve System, or the Board of Governors.

Federal Reserve Bank of St. Louis Working Papers are preliminary materials circulated to stimulate discussion and critical comment. References in publications to Federal Reserve Bank of St. Louis Working Papers (other than an acknowledgment that the writer has had access to unpublished material) should be cleared with the author or authors. 


\title{
Intergenerational Policy and the Measurement of Tax Incidence*
}

\author{
Juan Carlos Conesa \\ Stony Brook University
}

\author{
Carlos Garriga \\ Federal Reserve Bank of St. Louis
}

October 16, 2015

\begin{abstract}
We evaluate the ability of generational accounting to assess the potential welfare implications of policy reforms. In an intergenerational context policy reforms usually have redistributive, efficiency, and general equilibrium implications. Our analysis shows that when the policy reform implies changes in economic efficiency, generational accounts can be misleading not only about the magnitude of welfare changes, but also about the identity of who wins and who losses. In contrast the generational accounts correctly identify welfare changes when the policy reform has only a pure intergenerational redistribution component. We illustrate and quantify this issue in the context of widely considered policy reforms (substitution of consumption for labor taxation, and the increase of retirement age) and in a more general context of optimal policy.
\end{abstract}

Keywords: Generational accounts, optimal reforms, overlapping generations.

J.E.L. codes: E62, H21

${ }^{*}$ The authors thank the following for useful comments: Costas Azariadis, Tim Kehoe, Chris Phelan, B. Ravikumar, and the participants at the 2008 meetings of the SED, Bern, Edingurgh, Banco de España, Central Bank Hungary, European Central Bank, CERGE-EI, CUNY-Hunter College, European University Institute, ITAM, Universidad de Alicante, University of California at Santa Barbara, and Utah State University. The views expressed herein do not necessarily reflect those of the Federal Reserve Bank of St. Louis, the Federal Reserve System, the Board of Governors, or the regional Federal Reserve Banks. The authors can be reached via e-mail at Juan.Conesa@stonybrook.edu, and Carlos.Garriga@stls.frb.org 


\section{Introduction}

In most developed economies, the financing of entitlement programs or commitments to the existing generations (i.e., social security and health care) will likely pose very serious fiscal challenges in the near future. Many potential reforms involve substantial changes in economic efficiency and intergenerational redistribution. The magnitude of these fiscal adjustments, the distribution of the tax burden across different cohorts and the welfare implications depend on the specifics of the tax reforms. It is then essential to have reliable estimates of the implications of alternative reforms. ${ }^{1}$ A commonly used tool is generational accounting, first described in Auerbach, Gokhale, and Kotlikoff (1991), that measures the distribution of the tax burden across different cohorts (see Kotlikoff, 1992, 2002, for a full description of the methodology), comparing the lifetime tax bills (net of transfers) of present and future cohorts. ${ }^{2}$

This paper evaluates the ability of generational accounting metrics to capture the identity of the cohorts who benefit from or bear the cost of policy reforms. Using data generated by the model provides the perfect laboratory to measure tax incidence. Within the context of a theoretical model in the spirit of Auerbach and Kotlikoff (1987), we argue that when reforms generate large changes in efficiency the generational accounts do not identify well the identity and magnitude of welfare changes. We proceed by computing the dynamic response of our model economy to a given reform, take the model generated data and compute the generational accounts on the artificial data. The evaluation stage compares the performance of the model generational accounts with the model quantitative predictions about welfare changes for different cohorts.

Of course, this way of proceeding assumes exact knowledge of the general equilibrium effects and the behavioral responses to policies when computing the generational accounts. This might be the case when evaluating policies ex-post (once their implications are observed, if at all possible), but this is for sure not possible when trying to evaluate the potential impact of policies not yet implemented. Still we show that, even if we had all the correct information available in terms of behavioral responses and price implications, generational accounts might generate a misleading picture of the welfare implications of policies. The reason is that policies often imply changes in economic efficiency that for some cohorts would result in simultaneous increase in welfare and a larger tax burden.

To compare the compare generational accounts and welfare we use the following criteria. We will argue that the generational accounts capture the sign and magnitude of welfare

\footnotetext{
${ }^{1}$ The literature builds on the seminal contribution of Auerbach and Kotlikoff (1987). It is impossible to provide a comprehensive list of references here, see for example Altig et al. (2001); Conesa and Krueger (1999); Conesa, Kitao, and Krueger (2009); Fuster, Imrohoroglu, and Imrohoroglu (2007); or Nishiyima and Smetters (2007).

${ }^{2}$ Gokhale et al. (2000) analyze the U.S. use of the long-term projections of the Congressional Budget Office. The authors calculate the magnitudes of adjustment through alternative policies that could solve future imbalances. Other applications include a switch from income to consumption taxation (as in Altig et al., 2001) or Social Security privatization (as in Kotlikoff, Smetters, and Walliser, 2001), and a cross country analysis (as in Kotlikoff and Raffelheuschen, 1991).
} 
changes if, whenever generational accounting determines that a particular cohort will pay $X \%$ more taxes over its life-cycle (as a share of lifetime income), we observe that for that particular cohort there is a decrease in welfare roughly equivalent to an $X \%$ decrease in consumption over its life-cycle (as a share of lifetime income).

In our model economy, we consider first two specific reforms that have been widely discussed in the actual policy debate. The first reform is a switch from income to consumption taxation, as has been often discussed in the literature (see for example Altig et al., 2001). The second reform eliminates restrictions on labor market participation for individuals collecting social security benefits (i.e., the type of reforms that were implemented in the US in the late nineties). Within the context of our model economy, this second reform can also be interpreted as a delay in retirement age. We show that in the first reform (increasing consumption taxes and decreasing labor income taxes) the intergenerational redistribution component dominates, and then the generational accounts do a very good job of identifying the identity and magnitude of welfare changes. In contrast, in the second reform (allowing for people to work after age 65) efficiency considerations dominate, and we show that generational accounts do not perform well in identifying welfare changes.

Based on these results, we perform an additional experiment based on the optimal fiscal policy approach in overlapping generations economies of Erosa and Gervais (2002) and Garriga (1999). As in Conesa and Garriga (2008a,b), we solve for the optimal fiscal policy given an explicit target of intergenerational redistribution of welfare changes. This analysis helps to clarify the distinction between efficiency considerations and intergenerational redistribution. The reason is that this exercise brings the economy to the constrained Pareto frontier (thus maximizing constrained efficiency), while allowing for the explicit comparison of different points along that frontier (intergenerational redistribution). While the explicit policies that solve this programming problem might not be policies that are under consideration, we still believe the exercise is useful because of its ability to cleanly decompose the impact of reforms between their efficiency and redistributive components. In addition, it provides evidence that our conclusions are not an artifact of the specific policy reforms considered. Indeed, our exercise confirms the main insight from the evaluation of our two exogenous reforms: Generational accounting performs very well when comparing policies that imply different points along the constrained Pareto frontier, while it performs very poorly in evaluating policies that bring the economy from an interior point to the frontier.

Both our exogenous reforms and the optimal policy exercise highlight the main mechanism behind our quantitative results. Increasing efficiency, bringing the economy to the constrained Pareto frontier (in the case of optimal reforms) or closer to it (in the case of exogenous reforms), is mostly the result of changes in the age-profile of hours worked and consumption. When evaluating these types of reforms generational accounts are in general misleading, since welfare changes and the magnitude of the change in the net present value of consumption are very different objects. In contrast, redistributive reforms in general increase the age-profile of consumption of some cohorts at the expense of others. In that second case, generational accounts capture the change in the net present value of consumption and give 
an accurate picture of welfare changes of the reform.

The rest of the paper is organized as follows. Section 2 summarizes the methodology of generational accounting. Section 3 describes the benchmark model used in the analysis. Section 4 and 5 consider various exogenous and endogenous tax policy reforms. Section 6 concludes.

\section{The Methodology of Generational Accounting}

The generational accounting methodology was developed by Auerbach, Gokhale, and Kotlikoff (1991) with the objective of measuring the generational incidence of tax policy independent of fiscal taxonomy labels (see Kotlikoff $(1992,2002)$ for a full description of the methodology). The approach compares the lifetime net tax bills of present and future cohorts, and it also measures the change in the generational accounts implied by changes in fiscal policy. All these different tax burden measures can be compared independently of how fiscal deficits are calculated. An important aspect of the methodology is the evolution of population demographics in the government budget constraint and the measurement of generational imbalances. The ultimate goal is to prescribe tax policies that could correct any imbalance, so all generations bear a similar tax burden. A similar concept called "equal burden-sharing" is used by Bernanke (2006). This concept is interpreted to mean that the current generation and all future generations experience the same percentage reduction in per capita consumption.

For the description of the methodology we closely follow Kotlikoff (2002). The tax burden $b_{k, t}$ of a cohort born in period $k$ at time $t$ is measured as

$$
b_{k, t}=\sum_{s=\max (t, k)}^{k+d} R^{-(s-t)} \frac{\pi_{k, s}}{\pi_{k, t}} T A X_{k, s}
$$

The term $T A X_{k, s}$ represents the projected average net tax payments made in period $s$ by a cohort born at time $k$. The term $\pi_{k, s} / \pi_{k, t}$ describes the proportion of individuals of cohort $k$ alive at time $t$ who will also be alive at time $s$. Therefore, it represents an actuarial present value of the average amount of taxes paid (net of transfers) by the surviving members of cohorts born at time $k$. That includes expenditures in health care, education, and other

forms of transfer programs. However, it does not impute to any specific cohort the value of government expenditure in goods and services. The main reason is the difficulty in assigning the benefit of government purchases to different generations.

The intertemporal budget constraint of the government can be interpreted in terms of a metric for each cohort:

$$
\sum_{s=0}^{d} \mu_{t-s, t} b_{t-s, t}+\sum_{s=1}^{\infty} \frac{\mu_{t+s, t+s} b_{t+s, t+s}}{R^{s}}=D_{t}+\sum_{s=1}^{\infty} \frac{G_{t+s}}{R^{s}}
$$

where $\mu_{k, t}$ denotes the measure in period $t$ of cohorts born at time $k$. The term $b_{k, t}$ represents the per capita generational account in period $t$ for a generation born in period $k$. The first 
term in the left-hand includes all existing cohorts, while the second term adds together the generational accounts of unborn cohorts discounted at some rate $R$. The terms on the right hand side represent the government net debt $D_{t}$ (financial liabilities minus the sum of its financial assets and market value of public enterprises) and the present value of current and future government expenditures $\left\{G_{t+s}\right\}_{s=1}^{\infty}$.

Given the tax burden of the present generations $\left\{b_{t-s, t}\right\}_{s=0}^{d}$ and a projection of future expenditures $\left\{G_{t+s}\right\}_{s=1}^{\infty}$, it is possible to calculate as a residual the tax payments of future generations. Following this procedure it is possible to identify intergenerational imbalances

$\left(b_{t+s, t+s} \neq b_{t-s, t}\right)$ and compute what policy changes (and paid by what generation) might restore a balanced share of the burden. A common approach is to assume that productivity and wages grow at a constant rate $g>0$, so it is possible to calculate the growth-adjusted generational account of future generations denoted by $\bar{b}$. Formally,

$$
\sum_{s=0}^{d} \mu_{t-s, t} b_{t-s, t}+\sum_{s=1}^{\infty} \mu_{t+s, t+s} \bar{b}(1+g)^{s} R^{t-s}=D_{t}+\sum_{s=t}^{\infty} G_{s} R^{t-s} .
$$

This expression is used to determine fiscal adjustments (taxes, transfers, or government expenditure) that achieve an intergenerational balance for future cohorts.

\section{The Benchmark Economy and the Measurement of Tax Incidence}

This section explains in detail the methodology used to evaluate the performance of the generational accounting metrics. Using data generated by a standard general equilibrium overlapping generations model calibrated to the US economy, the model provides the perfect laboratory to measure tax incidence.

\subsection{The Benchmark Economy}

The economy is populated by a measure of households who live for a maximum of $I$ periods and grows at rate $n$. The term $\varphi_{i}$ represents the conditional survival probability, that is $\varphi_{i}=\operatorname{Prob}\left(\right.$ alive at age $i+1 \mid$ alive at age $i$ ). Therefore, $s_{1}=1$, and $s_{i}=\varphi_{1} \cdot \varphi_{2} \cdot \ldots \cdot \varphi_{i-1}$ is the unconditional probability of being alive at age $i$. The term $\mu_{i}$ denotes the measure of households of age $i$, computed as $\mu_{i}=\left(\varphi_{i} \mu_{i-1}\right) /(1+n)$. For simplicity we are abstracting here from demographic changes.

Preferences of a household born in period $t$ depend on the stream of consumption and leisure this household will enjoy. Thus, expected utility is given by

$$
U\left(c^{t}, l^{t}\right)=\sum_{i=1}^{I} \beta^{i-1} s_{i} u\left(c_{i, t+i-1}, 1-l_{i, t+i-1}\right),
$$

where $\beta>0$ represents the discount factor. The utility function is twice differentiable in each argument and satisfies the usual Inada conditions. Each household owns one unit of time in 
each period that they can allocate for work or leisure. One unit of time devoted to work by a household of age $i$ translates into $\varepsilon_{i}$ efficiency units of labor in the market in exchange for a competitive wage $w_{t}$. They rent assets $a_{i, t}$ to firms or the government in exchange for a competitive price, $r_{t}$, and decide how much to consume and save of their disposable income. The sequential budget constraint for a working age household is given by

$$
c_{i, t}+(1+x) a_{i+1, t+1}=w_{t} \varepsilon_{i} l_{i, t}+\left(1+r_{t}\right) a_{i . t}-\Phi_{i, t}
$$

where $\Phi_{i, t}$ represents total taxes paid to the government and $x$ denotes an exogenous rate of productivity growth. Upon retirement at age $i_{r}$, households do not work and receive a public pension, in a lump-sum fashion. Their budget constraint is

$$
c_{i, t}+(1+x) a_{i+1, t+1}=p_{t}+\left(1+r_{t}\right) a_{i . t}-\Phi_{i, t}
$$

The simplifying assumption here is that explicit transfers are only collected upon retirement, and the rest of government expenditure is not specifically allocated to any particular cohort (we could think of it as a public good that enters utility separately).

Notice that we are assuming compulsory retirement in the benchmark economy. The alternative interpretation of a mandatory retirement rule is to consider a confiscatory tax on labor income for ages $i_{r}$ and above. This alternative interpretation makes very explicit the distortionary impact of such an institutional arrangement. We will explicitly consider the impact of removing this restriction in the evaluation of policy reforms.

The production possibility frontier is given by an aggregate production function $Y_{t}=$ $F\left(K_{t}, A_{t} L_{t}\right)$, where $K_{t}$ denotes the capital stock in period $t$ and $L_{t}=\sum_{i=1}^{I} \mu_{i} \varepsilon_{i} l_{i t}$ is aggregate labor measured in efficiency units. Aggregate labor efficiency, $A_{t}$, grows at an exogenous rate of technological progress $x$. The function $F$ displays constant returns to scale, is monotonically increasing, strictly concave, and satisfies the Inada conditions. The capital stock depreciates at a constant rate $\delta$. The aggregate resource constraint is given by

$$
\sum_{i=1}^{I} \mu_{i} c_{i t}+(1+x)(1+n) k_{t+1}-(1-\delta) k_{t}+g_{t} \leq f\left(k_{t}, \sum_{i=1}^{I} \mu \varepsilon_{i} l_{i t}\right)
$$

where aggregate variables are deflated by the growth rate of output on a balanced growth path $(1+x)(1+n)$.

The government influences this economy through administration of the social security program and the general budget. In the benchmark economy, these two programs are operated with different budgets. Then, pensions $p_{t}$ are financed through a payroll tax $\tau_{t}^{p}$ and the social security budget is balanced:

$$
\tau_{t}^{p} w_{t} \sum_{i=1}^{I} \mu_{i} \varepsilon_{i} l_{i t}=p_{t} \sum_{i=i_{r}}^{I} \mu_{i}
$$

On the other hand, the government tax revenue consists of consumption taxes, $\tau_{t}^{c}$, labor income taxes, $\tau_{t}^{l}$, capital income taxes, $\tau_{t}^{k}$, and the issuance of public debt, $B_{t}$, to finance 
an exogenously given stream of per-capita government consumption, $g_{t}$. The government expenditure constraint is given by

$$
(1+x)(1+n) B_{t+1}+T_{t}=g_{t}+\left(1+r_{t}\right) B_{t}
$$

where

$$
T_{t}=\tau_{t}^{c} \sum_{i=1}^{I} \mu_{i} c_{i t}+\tau_{t}^{l}\left(1-\tau_{t}^{p}\right) w_{t} \sum_{i=1}^{I} \mu_{i} \varepsilon_{i} l_{i t}+\tau_{t}^{k} r_{t} \sum_{i=1}^{I} \mu_{i} a_{i t}+\sum_{i=1}^{I} \mu_{i}\left(1-\varphi_{i-1}\right) a_{i t}
$$

Since there is survival uncertainty and annuity markets are not available, we assume that the government collects the assets of the deceased households.

A market equilibrium in the baseline economy is a sequence of prices and allocations such that (i) all consumers maximize utility subject to their corresponding budget constraints given policies and equilibrium prices, (ii) firms maximize profits given prices, (iii) the government and social security budgets are satisfied, and (iv) markets clear and feasibility constraints are satisfied.

\subsection{The Parameterization of the Benchmark Economy}

The choice of functional forms is fairly conventional. The household's utility function takes the form:

$$
u(c, l)=\frac{\left(c^{\gamma}(1-l)^{1-\gamma}\right)^{1-\sigma}}{1-\sigma}
$$

where $\gamma \in(0,1)$ denotes the relative weight of consumption in the utility function and $\sigma>0$ governs the concavity of the utility function. These preferences have an implied intertemporal elasticity of substitution in consumption equal to $1 /(1-(1-\sigma) \gamma)$.

The production function is Cobb-Douglas, $Y_{t}=K_{t}^{\alpha}\left(A_{t} L_{t}\right)^{1-\alpha}$, where $\alpha$ represents the capital income share. Labor efficiency, $A_{t}$, grows at rate of $x=0.0175$ per year.

A period in the model is equivalent to 5 years. Households in the model live up to a maximum of 14 periods and retire at age 10. In chronological time, the active life of a household starts at age 20 , retires at 65 , and lives at most to age 89 . The survival probabilities, $\varphi_{i}$, are from Bell and Miller (2002), with the assumption that households die with probability 1 when reaching age 90 . The mass of newborn households (and hence the total mass of households) grows at an annual rate $n=0.011$. The endowment of efficiency units is from the Hansen (1993) estimates.

In the benchmark economy, the government runs two completely independent budgets. One is the social security budget, which operates on a balanced budget. The payroll tax is from the data and is equal to 10.5 percent of labor income, which is Old-Age and Survivors Insurance ([OASI], excluding Medicare and disability insurance). The assumptions about demographics (implying a ratio of the population over 65 to the working age population of 24 percent), together with the balanced budget condition, directly determine the amount of the public retirement pension, which is 43 percent of the average gross labor income. 
The level of government expenditure is exogenously given. It is financed through a consumption tax of 5 percent; a marginal tax on capital income of 33 percent; and a tax on labor income (net of social security contributions) of 16 percent. These effective tax rates have been estimated using the methodology proposed by Mendoza, Razin, and Tesar (1994). The government issues public debt to satisfy its sequential budget constraint.

The calibration strategy matches five model parameters with five data targets prior to 2008. The targets are: 1) The aggregate capital stock as defined by the level of fixed assets in the Bureau of Economic Analysis (BEA) statistics. In the calibration, the capital-to-output ratio is 3 in yearly terms. 2) The ratio of outstanding government (federal, state, and local) debt to gross domestic product (GDP) fluctuates around 0.5 percent (in yearly terms). 3) Depreciation is also from the BEA statistics and averages 12 percent of GDP. 4) Capital income share is measured from the national accounts and averages 34 percent. 5) Households allocate an average of one-third of their time to market activities. The parameter governing the weight on consumption in utility, in conjunction with the curvature parameter in the utility function, is consistent with a consumption intertemporal elasticity of substitution of 0.5 (about an average value of the empirical estimates obtained in the literature).

Notice that all parameters are jointly determined to match the empirical targets. The implied parameters that satisfy the targets are as follows: The discount factor is $\beta=1.0375$, the consumption share is $\gamma=0.31$, the curvature parameter in the utility function is $\sigma=4$, the capital share in the production function is $\alpha=0.34$, and the depreciation rate is $\delta=$ 0.044 .

The level of government consumption is obtained in equilibrium to match the level of debt observed in the data for pre-crisis times (50 percent of output). Given this parameterization, government expenditure is 23.7 percent of output in equilibrium, and social security payments amount to 6.9 percent of output.

\subsection{The Generational Accounts of the Benchmark Economy}

The construction of generational accounting metrics using the data from the model closely follows the work of Fehr and Kotlikoff (1996) and Kotlikoff (2002). It is necessary to determine the net tax outlets (taxes minus transfers properly discounted) for each generation. For a given tax policy, the generational accounts for a cohort of newborn individuals is represented by

$$
b_{t}=\sum_{i=0}^{I-1} \frac{q_{t+i}}{q_{t}}\left[\tau_{t+i}^{c} c_{i t+i}+\tau_{t+i}^{l}\left(1-\tau_{t+i}^{p}\right) w_{t+i} \varepsilon_{i} l_{i, t+i}+\tau_{t+i}^{k} r_{t+i} a_{i, t+i}-p_{t+i}\right]
$$

where $q_{1}=1$ and $q_{t}=q_{t-1} /\left(1+\left(1-\tau_{t}^{k}\right) r_{t}\right)$ for $t=2,3, \ldots$ In contrast to empirical applications, the theoretical model offers a natural discount rate because the market-clearing interest rate can be used. In equilibrium, the government's intertemporal budget constraint is always satisfied. However, the implied individual generational accounts and imbalances need not be consistent with the government's budget constraint unless the appropriate discount 
rate is used. ${ }^{3}$ There is an equivalent expression for the cohorts already born with a shorter life-span. Figure 1 summarizes the model-implied generational accounts of the benchmark economy. The generational accounts have been normalized by life-time gross income, as a consequence the value on the axis represents the percentage of taxes or transfers as a share of remaining lifetime income. For the initial generations alive, the metrics capture not a total lifetime bill but, rather, remaining lifetime bills. The generational accounts are usually positive for working cohorts but negative for retired cohorts.

For the baseline policy, the model generates a vector of utility entitlements $\left\{\widehat{U}_{j}\right\}$ that will be used to compare changes in welfare with the generational accounts.

\section{Exogenous Intergenerational Policy Reforms}

This section considers two parametric tax reforms often studied in the literature. The first one follows Altig et al. (2001) and consists of a partial replacement of labor income taxes with consumption taxes. The second reform allows individuals to start collecting pensions at age 65 and still continue working until age 70 .

We need to make sure that our measure of welfare changes and our measure of the changes in the generational accounts are comparable. The natural way to compute the magnitude of welfare changes is to use the consumption equivalent variation (the percentage by which consumption in the benchmark economy should change in all remaining periods for a given cohort to attain the same welfare level than would be attained under the proposed reform). We measure the change in the generational accounts as the difference in lifetime taxation relative to remaining lifetime (gross) income. Notice that absent changes in relative prices or behavioral responses a reform that decreases my remaining lifetime income by $10 \%$ should imply a welfare change equivalent to a decrease of $10 \%$ in consumption. In that sense our measurement of welfare changes and the changes in tax burden are consistent.

The timing of all the exogenous reforms operates as follows. At time $t=0$, the economy is in steady state under the baseline policy and no fiscal reform has been anticipated by households. At $t=1$, the government announces and implements the new policy. The macroeconomic variables adjust over time until the economy converges to the new steady state under the new policy regime. Across policy reforms, the government expenditure is maintained constant and consumption taxes are adjusted to balance the budget each period.

\subsection{Exogenous Reform 1: Substitute Consumption for Income Taxes}

The first tax reform reduces the baseline labor-income taxes by half (from 30 percent to 15 percent). The fall in tax revenue collection is compensated by an endogenous increase in consumption taxes to balance the budget. The reform is evaluated in a closed and in

\footnotetext{
${ }^{3}$ See Conesa and Garriga (2013) for a specific discussion of this issue.
} 
a small open economy. The last option allows us to control for the impact of changes in relative prices. Figure 2 describes the nature of the policy change and the evolution of the main macroeconomic aggregates and individual decisions along the transition path to the new steady state.

The macroeconomic implications of the reform are straightforward. First, this reform has an immediate intergenerational redistributive component, since it clearly redistributes from the old in favor of the relatively young. In addition, the distortions on the labor supply of the working age people are reduced under the new policy. The reform is not neutral and aggregate efficiency increases. In the long run the economy converges to a steady state with a higher capital stock and higher wages. The decline in the tax burden of newborn working generations increases their lifetime utility.

The top part of Figure 3 compares the generational accounts under the baseline policy and the tax reform. The straight bar in 1995 separates the initial generations alive at the start of the reform from the newborn cohorts under the new tax policy regime in 2015 . The policy reform increases the tax burden of retired individuals that face higher consumption taxes than with the baseline policy. This is captured by an upward shift of the generational metric for the existing cohorts (including some of the middle age workers) at the start of the reform. The newborn cohorts face lower taxation over their lifetime and this is captured by a downward shift of the generational accounts.

The bottom part of Figure 3 compares individuals' welfare, measured in terms of consumption equivalence, with the change in tax incidence relative to (gross) lifetime income under the baseline policy. The negative relationship between these lines suggests that the metrics successfully capture the identity of the winners and losers of the policy reform. Those who suffer a higher tax burden are those that indeed suffer a welfare loss. The newborn cohorts face a lower tax burden and the initial generations alive bear the cost of the reform. The cost of the reform is particularly large on retired individuals that have no ability to avoid consumption taxes. The welfare cost of the reform is lower for individuals that are already working when the reform takes place. These individuals have the ability to adjust the labor supply and the pattern of savings over a longer horizon. The metric captures the decreasing burden for these individuals. In this particular policy experiment there are no substantial discrepancies between the metrics and welfare measurement, especially for generations currently alive. This is the case because this reform implies mostly a redistributive component, especially in the short run. This reform generates non-trivial adjustments in the relative prices. On impact capital is inelastic and the reduction of labor taxation increases the labor supply, reducing wages.

To evaluate the impact of changes in relative prices consider the same reform but in a small open economy. The path of taxes and the main macroeconomic aggregates are summarized in Figure 4 and the generational accounts and welfare are depicted in Figure 5. The absence of price effects requires a smaller adjustment of consumption taxes, generating larger welfare effects relative to the closed economy. The exercise illustrates that the levels of the generational accounts are affected by the response of relative price, changing the extent 
of redistribution between current and future generations. In this case, the metrics correctly identify the identity and the approximate magnitude of welfare changes even better when we abstract from general equilibrium price effects.

\subsection{Exogenous Reform 2: Extension of Working Age}

In the baseline economy workers have mandatory retirement at 65 years old, after retirement they start collecting social security payments. In this section we evaluate a policy reform that eliminates mandatory retirement and allows individuals to collect the retirement pension while working between ages 65 and 70. The efficiency units are assumed to be the same as for age $65 .{ }^{4}$ The implications for the tax system and the economy are summarized in Figure 6.

The extension of the working age implies that individuals work a bit more over the life-cycle but also save more, resulting in a minimal adjustment in relative prices. The welfare gains associated with the policy reform come from the improved ability to smooth consumption over the life-cycle. The delay in the retirement age increases the tax revenue because these workers continue to contribute to the social security system (despite receiving a retirement transfer) and pay labor income taxes, allowing for a decline in consumption taxation.

The effects of this policy on the generational accounts and welfare are summarized in Figure 7. Clearly, the elimination of mandatory retirement increases welfare for all of the individuals. Individuals already retired when the reform is in place pay lower consumption taxes and have higher welfare. The utility gains for these cohorts are well captured by the reduction in their lifetime tax burden. All future generations will pay higher taxes over the lifetime because the additional year working generates an increase in lifetime taxation. However, the ability to change the life-cycle profile of consumption and leisure generates an increase in lifetime utility. Welfare increases despite the increase in taxation, and that implies a discrepancy between the change in generational accounts and individuals' welfare.

Notice that mandatory retirement is equivalent to a 100 percent tax on labor income after age 65 . In that sense, the elimination of compulsory retirement rules is equivalent to a reduction of the tax from 100 percent to 16 percent, which is the benchmark tax rate on labor income. Clearly a 100 percent tax on labor income is on the wrong side of the Laffer curve, and any reduction in that tax rate will increase welfare and tax revenues at the same time. This effect, even if the response of hours worked is not very large, explains the divergence (not only in magnitude, but also in sign) between changes in generational accounts and welfare changes.

These two policy experiments provide some indications of when generational accounts successfully capture the identity of the cohorts that benefit and the magnitude of welfare changes of policy reforms. The next section performs an additional experiment solving for the optimal fiscal policy given an explicit target of intergenerational redistribution of

\footnotetext{
${ }^{4}$ The key findings are qualitatively the same assuming decreasing efficiency units after the retirement age.
} 
welfare changes. In this context, the presence of government debt is a very useful tool for redistributing welfare gains across different cohorts.

\section{Endogenous Intergenerational Policy Reforms}

The use of optimal taxation helps to clarify the distinction between efficiency considerations and intergenerational redistribution. The optimal policy brings the economy to the constrained Pareto frontier (thus maximizing constrained efficiency). Changes in the distribution of social weights allow for the explicit comparison of different points along that frontier (intergenerational redistribution).

The key insight is to use optimal fiscal policy to determine endogenously the least distortionary way of financing a given level of government expenditures and utility entitlements. The applications in Conesa and Garriga (2008a,b) identify the best way to finance the transition from an unfunded social security system to a privatized social security system guaranteeing Pareto improvements for all current and future cohorts. The experiments in this section focus on disentangling redistributive implications from efficiency implications of the optimal policy.

The general intuition for this problem is consistent with the previous policy experiments because the main source of efficiency gains comes from the minimization of labor supply distortions (substitute consumption for income taxes and the extension of working age). The efficiency gains then are redistributed between current and future cohorts through the optimal use of a debt transfer scheme. The existence of government debt is very useful because it allows the government to transfer resources across time directly instead of using the tax system for that purpose.

The distribution of welfare gains associated with the optimal policy is arbitrarily chosen through the intergenerational weights in the social welfare function and the entitlement or promise keeping constraint. We use a utilitarian function of the form $\sum_{t=1}^{\infty} \lambda^{t-1} U\left(c^{t}, l^{t}\right)$, where the key parameter is $\lambda \in(0,1)$, the weight on next period generation relative to today. The social weight on the initial generations alive at the start of the reform at $t=1$ is represented using promise keeping constraints:

$$
\sum_{i=j}^{I} \frac{s_{i}}{s_{j}} \beta^{i-j} U\left(c_{i, i-j+1}, l_{i, i-j+1}\right) \geq \mu(\kappa) \widehat{U}_{j}, \quad j=2, \ldots, I .
$$

The initial generations alive are either currently receiving transfers (retirees) or were promised some transfers in the near future (current workers). These recipients have no explicit weight in the objective function, but the promised welfare under the old tax policy $\hat{U}_{j}$ is viewed as an entitlement. The government is committed to deliver some welfare gain of $\kappa$ units (measured in consumption equivalents) to all initial generations. The function $\mu(\kappa)$ depends on preference parameters and transforms the desired level of consumption equivalent changes into the correct utility metric. Given our preference specification, a simple formula 
translates welfare gains in consumption equivalent units into utility: $\mu(\kappa)=\kappa^{\gamma(1-\sigma)}$.

Timing: At time $t=0$, the economy is in the steady state under the baseline policy and no fiscal reform has been anticipated by households. At $t=1$, the government implements the optimal policy by determining age-dependent labor income taxes for each cohort, eliminating mandatory retirement and pensions, and issuing compensatory transfers to the initial generations financed with government debt. The aggregate variables adjust over time until the economy converges to the new steady state under the new optimal policy.

The dynamics of the economy depend entirely on the degree of intergenerational redistribution governed by the pair $(\lambda, \kappa)$. These pairs will be constrained to guarantee that future generations are not worse off than in the initial steady state. For low values of $\lambda$, the long-run capital stock would be so low that this condition would not be satisfied. This restricts the range of admissible values for $\lambda$ to values high enough so that the steady state solution of the government problem for a newborn yields higher utility than in the benchmark economy. Similarly, the level of welfare gains accruing to initial generations has an upper bound that guarantees that the promised utility constraint is not violated along the transition path. If the pair $(\lambda, \kappa)$ cannot guarantee both conditions, then the policy is dismissed as infeasible from a redistributive point of view.

Following the primal approach, the programming problem that determines the optimal policy can be written as:

$$
\begin{gathered}
\max \sum_{t=1}^{\infty} \lambda^{t-1} U\left(c^{t}, l^{t}\right), \\
\text { s.t. } \quad \sum_{i=1}^{I} \mu_{i} c_{i t}+(1+x)(1+n) k_{t+1}-(1-\delta) k_{t}+g_{t} \leq f\left(k_{t}, \sum_{i=1}^{I} \mu_{i} \varepsilon_{i} l_{i t}\right), \quad \forall t, \\
\sum_{i=1}^{I} s_{i} \beta^{i-1}\left[c_{i, t+i-1} U_{c_{i, t+i-1}}+l_{i, t+i-1} U_{l_{i, t+i-1}}\right]=0, \quad t \geq 1, \\
\sum_{i=j}^{I} \frac{s_{i}}{s_{j}} \beta^{i-j}\left[c_{i, i-j+1} U_{c_{i, i-j+1}}+l_{i, i-j+1} U_{l_{i, i-j+1}}\right]=\frac{U_{c_{j, 1}}}{1+\bar{\tau}_{1}^{c}}\left[\left(1+\left(1-\bar{\tau}_{1}^{k}\right)\left(f_{k, t}-\delta\right)\right) \widehat{a}_{j, 1}+\widetilde{p}_{i, 1}\right], \quad j=2, \ldots, I, \\
\frac{U_{c_{1, t}}}{\varphi_{1} U_{c_{2, t+1}}}=\frac{U_{c_{2, t}}}{\varphi_{2} U_{c_{3, t+1}}}=\ldots=\frac{U_{c_{I-1, t}}}{\varphi_{I-1} U_{c_{I, t+1}}}=\frac{\beta}{1+x}\left[1+\left(1-\bar{\tau}_{1}^{k}\right)\left(f_{k, t+1}-\delta\right)\right], \quad t \geq 1, \\
\sum_{i=j}^{I} \frac{s_{i}}{s_{j}} \beta^{i-j} U\left(c_{i, i-j+1}, l_{i, i-j+1}\right) \geq \mu(\kappa) \widehat{U}_{j}, \quad j=2, \ldots, I .
\end{gathered}
$$

The optimization problem takes as given $k_{1}, \bar{\tau}_{1}^{c}$, and $\bar{\tau}_{1}^{k}$ and solves for the compensatory transfers $\widetilde{p}_{i, t} \in R_{+}$to each of the initial generations alive and individual allocations $\left\{\left\{c_{i, t}, l_{i, t}\right\}_{i=1}^{I}\right\}_{t=1}^{\infty}$.

The first constraint is the feasibility constraint. The second and the third are the implementability conditions for both newborns and cohorts initially alive. The fourth constraint reflects the assumption that capital income taxes are always constant. The fifth constraint is the promise-keeping constraint of the initial cohorts that we discussed before. There are two reasons to abstract from capital income taxes. First, the additional welfare gains associ- 
ated with this tax instrument are negligible, especially once you allow for age-specific labor income taxes (a detailed discussion is Conesa and Garriga, 2008a). Second, abstracting from the choice of capital-income taxes eases the comparison with the case of exogenous reforms, where we did not use this tax instrument either.

The optimal intergenerational policy is solved for different combinations of $\lambda \in\{0.97,0.98\}$ and $\kappa \in\{1.00,1.02,1.04\}$. For the parameterization of the benchmark economy, the range of feasible values that can generate widespread welfare gains is quite limited. Values of $\lambda$ slightly below 0.97 imply that it is impossible to guarantee that generations born in the future steady state would be better off with the reform. Similarly, it is not possible to provide to the initial generations welfare gains larger than $4 \%$ if future cohorts must be guaranteed a level of welfare at least as high as with the benchmark policy. Values of $\kappa$ below 1 would imply a partial default on the utility entitlements of the initial cohorts.

For the evaluation of the metrics, it is useful to distinguish between what we call "Pareto efficient reforms" and "Pareto redistributive reforms". By the first we refer to the implementation of optimal policies relative to the benchmark economy, i.e. bringing the economy from an interior point to the constrained Pareto frontier. By "Pareto redistributive reforms",we will refer to comparisons of the optimal policy when we change the distribution of welfare gains, i.e. we compare different points in the constrained Pareto frontier.

For the case of $\lambda=0.97$ and $\kappa=1.00$, the dynamic paths of generational accounts and welfare under the baseline economy and the optimal intergenerational policy are shown in Figure 8. Under the benchmark policy the welfare of current and future generations remains unchanged and the generational accounts are the same for all newborn cohorts. ${ }^{5}$ The optimal intergenerational policy compensates the initial generations alive and their welfare is exactly the one of the benchmark economy. Given the discount rate of the government most of the efficiency gains are distributed to the newborn cohorts around 2005-25. Notice that the value of $\lambda=0.97$ leaves future newborns with a level of welfare very close to that of the benchmark economy. Lower values of $\lambda$ would imply welfare losses for these cohorts and are not considered in our exercise.

The bottom panel of Figure 8 reveals that the generational accounts fail to capture the identity and the magnitude of the welfare changes. By construction, all the initial cohorts are indifferent between the baseline and the optimal intergenerational policy, but the generational accounts imply that individuals born before 1980 are paying the cost of the reform (their tax burden increases). The oldest cohorts who were net recipients (negative generational accounts) will receive less, and those who are net contributors will contribute more.

To understand the main finding it is important to identify the sources of efficiency gains, which lie in the elimination of distortions. During the transition path, hours worked increase for almost all cohorts (initial and future newborns). The reduction in leisure is compensated

\footnotetext{
${ }^{5}$ In a changing environment (for example due to a demographic transition), it would be necessary to specify the path of policy for the baseline economy, and utility entitlements would be changing for future generations.
} 
by an increase in consumption, which is large for the generations very close to retirement (age 55). As a result individuals are either indifferent (or better off in the case of future generations), while they bear a larger tax burden. The logic is the same as for our experiment of eliminating the distortion associated with mandatory retirement.

Now consider "Pareto redistributive reforms" that vary the extent of welfare gains for existing cohorts (adjusting $\kappa>1$ ) for a given intergenerational discount rate $\lambda=0.97$. Figure 9 clearly shows an intergenerational tension: As the compensation of the initial generations increases, the welfare gains of newborns during the transition periods needs to be reduced. As the size of the entitlements of existing generations increases, the newborn generations during the transition will face higher taxation to pay for these obligations and hence their welfare gains are smaller. When comparing across these different policy options, we see that the magnitude and the identity of welfare changes are consistent with the generational accounts.

The larger the value of the parameter $\kappa$, the more initial cohorts are compensated in terms of consumption. However, the shape of the consumption and leisure profile is not significantly affected by the value of the parameter $\kappa$ (see Figure 10). The life-cycle patterns of consumption and hours worked of future generations have a very similar shape. The optimal policy adjusts the distribution of welfare gains through the use of debt, by repaying the debt earlier or later.

The parameter $\lambda$ is very critical in determining the distributional gains of the immediate and future newborns. The intergenerational tension between the short-run and the longrun is more evident when the intergenerational weight is increased from $\lambda=0.97$ to $\lambda=$ 0.98. In this case, the policymaker is more patient and attaches a much larger weight to future generations, but the ability to deliver more consumption depends on the size of the entitlements to the existing cohorts. The distribution of welfare and the generational accounts in this case are summarized in Figure 11. The shift in the weight of the social welfare function illustrates a clear intergenerational trade-off in the assignment of welfare gains. For the low lambda, all the welfare gains are front loaded whereas in this case the gains are back loaded with long-run values around 10 percent. The choice of lambda affects the intergenerational distribution of welfare gains, but the evaluation of the reforms using generational accounts reveals the same problem in both cases. The new tax policies generate sizable efficiency gains, and as a result the generational accounts fail to identify the cohorts that benefit from the reform. In the case of "redistributive reforms"shown in Figure 12, the metrics seem to perform as well as in the case illustrated in Figure 9. Conditional on the reform, changes in the redistribution of welfare gains are well captured by the generational accounts. Increasing the entitlements of the existing cohorts makes the relative relationship with the government more favorable for these individuals and less favorable for future cohorts.

The compensation scheme for the entitlement programs has important implications for the macroeconomy both in the short and long-run. The macroeconomic aggregates depend critically on the values of $\lambda$ and $\kappa$. For example, the combination of a low value of $\lambda$ and a high value of $\kappa$ implies that the government places a higher weight on the current generations 
(relative to future ones), and the initial generations alive need to be overly compensated. As a result, resources for the current generations will increase relative to those for future cohorts, which must devote a large fraction of their total resources to meet the interest payments of the bonds originated to compensate the initial cohorts. This trade-off is very explicit in Figure 13 that shows the dynamics of aggregate output and the debt-to-output ratio.

In this model, despite the different dynamics of macroeconomic aggregates (i.e., output and debt), the optimal tax rates solving the government's problem are not very different. Figure 14 plots the evolution of the average labor income tax in each case. The optimal labor supply distortions imply subsidies, especially for the oldest cohorts during the initial periods on the transition path. Over time, the initial cohorts disappear and it is optimal to tax labor again, repaying some fraction of the debt issued. The optimal repayment of debt depends on the intergenerational weights, but the pattern of optimal labor income taxes is essentially the same.

\section{Conclusions}

One of the most widely used tools for policy evaluation in practice is generational accounting. This approach has the advantage that the accounts are easy to compute, since no assumptions about preferences or technology are needed.

This paper evaluates the ability of generational accounting metrics to capture the identity of the cohorts who benefit from or bear the cost of policy reforms. Using data generated by the model provides the perfect laboratory to measure tax incidence. Our analysis suggests that when the policy reforms imply changes in economic efficiency, the generational accounting methodology fails to identify the magnitude of the welfare changes and even the sign of welfare changes for many cohorts. In contrast, when the policy reform involves only intergenerational redistribution, the generational accounts provide reasonable estimates of the magnitude of welfare changes for all cohorts. We reach this conclusion after comparing welfare implications of our artificial economy with the generational accounts constructed from our model-generated data.

Improvements in efficiency often involve a change in the age-profile of consumption and hours worked. In contrast, redistributive reforms shift up the age-profile of consumption of some cohorts relative to others. That is the reason why generational accounting is biased in evaluating the welfare implications of efficiency enhancing reforms. Our quantitative results show that the bias can be large.

In the end, in terms of policy evaluation in practice, it seems very hard to determine exante whether or not a particular policy proposal involves efficiency considerations in addition to the more obvious redistributive considerations. Moreover, forecasting behavioral responses seems extremely hard without the use of a model. Probably only the full specification and analysis of a model can help us in determining the efficiency impact and behavioral responses of policies, but in doing so the model would directly provide welfare measures to assess the 
impact of the policy reform.

\section{References}

Altig, D., L.J. Kotlikoff, K. Smetters, and J. Walliser (2001), "Simulating Fundamental Tax Reform," American Economic Review, June 2001, pp. 574-595.

Auerbach, A.J. and L.J. Kotlikoff (1987), Dynamic Fiscal Policy, Cambridge University Press.

Auerbach, A.J., J. Gokahale, and L.J. Kotlikoff (1991), "Generational Accounts: A Meaningful Alternative to Deficit Accounting," in D. Bradford, Ed., Tax Policy and the Economy, vol. 5, pp. 55-110. Cambridge, MA: MIT Press.

Bell, F., and M. Miller (2002), Life Tables for the United States Social Security Area 1900-2100, Office of the Chief Actuary, Social Security Administration.

Bernanke, B. (2006). "The Coming Demographic Transition: Will We Treat Future Generations Fairly?" Presented at the Washington Economic Club, Washington, DC, October 4, 2006; www.federalreserve.gov/newsevents/speech/bernanke20061004a.htm

Conesa, J.C., and C. Garriga (2008a), "Optimal Fiscal Policy in the Design of Social Security Reforms," International Economic Review, 49(1), pp. 291-318.

Conesa, J.C., and C. Garriga (2008b), "Optimal Response to a Transitory Demographic Shock," in De Menil, G., R. Fenge, and P. Pestieau, Eds., Pension Strategies in Europe and the United States, pp. 87-113. CESifo-MIT Press, Cambridge, MA.

Conesa, J.C., and C. Garriga (2013), "Intertemporal Discounting and Policy Selection," Federal Reserve Bank of St. Louis Review, .

Conesa, J.C., S. Kitao, and D. Krueger (2009), "Taxing Capital? Not a Bad Idea after All!," American Economic Review, 99(1), pp. 25-48.

Conesa, J.C., and D. Krueger (1999), "Social Security Reform with Heterogeneous Agents," Review of Economic Dynamics, 2, pp. 757-795.

Erosa, A., and M. Gervais (2002), "Optimal Taxation in Life-Cycle Economies," Journal of Economic Theory, 105, pp. 338-369.

Fehr, H., and L.J. Kotlikoff (1996), "Generational Accounting in General Equilibrium," FinanzArchiv, 53(4), pp. 1-27.

Feldstein, M., and J.B. Liebman (2002), "Social Security," in Auerbach, A.J. and M. Feldstein, Eds., Handbook of Public Economics, vol. 4, pp. 2245-2324. Elsevier Science, Amsterdam.

Fuster, L., A. Imrohoroglu, and S. Imrohoroglu (2007), "Elimination of Social Security in a Dynastic Framework," Review of Economic Studies, 74(1), pp. 113-145.

Garriga, C. (1999), "Optimal Fiscal Policy in Overlapping Generations Models," Mimeo.

Gokhale, J., B. Page, J. Potter, and J. Sturrock (2000), "Generational Accounts for the U.S.-An Update," American Economic Review, 90(2), pp. 293-296.

Hansen, G.D. (1993), "The Cyclical and Secular Behaviour of the Labour Input: Comparing Efficiency Units and Hours Worked," Journal of Applied Econometrics, 8(1), 71-80. 
Kotlikoff, L.J. (1992), Generational Accounting: Knowing Who Pays, and When, for What We Spend. Free Press, New York.

Kotlikoff, L.J. (2002), "Generational Policy," in Auerbach, A.J., and M. Feldstein, Eds., Handbook of Public Economics, pp. 1983-1932. North Holland, Amsterdam.

Kotlikoff, L.J., and B. Raffelheuschen (1991), "Generational Accounting Around the Globe," American Economic Review, 89, pp. 161-166.

Kotlikoff, L.J., K. Smetters, and J. Walliser (2001), "Distributional Effects in a General Equilibrium Analysis of Social Security," in M. Feldestein and J. Liebman, Eds., The Distributional Effects of Social Security Reform. University of Chicago Press, Chicago.

Mendoza, E., A. Razin, and L.L. Tesar (1994), "Effective Tax Rates in Macroeconomics: Cross-Country Estimates of Tax Rates on Factor Incomes and Consumption," Journal of Monetary Economics. 34, pp. 297-323.

Nishiyama S., and K. Smetters (2007), "Does Social Security Privatization Produce Efficiency Gains?," Quarterly Journal of Economics, 122(4), pp. 1677-1719. 


\section{Figures}

Figure 1: Benchmark Economy Generational Accounts (GA)

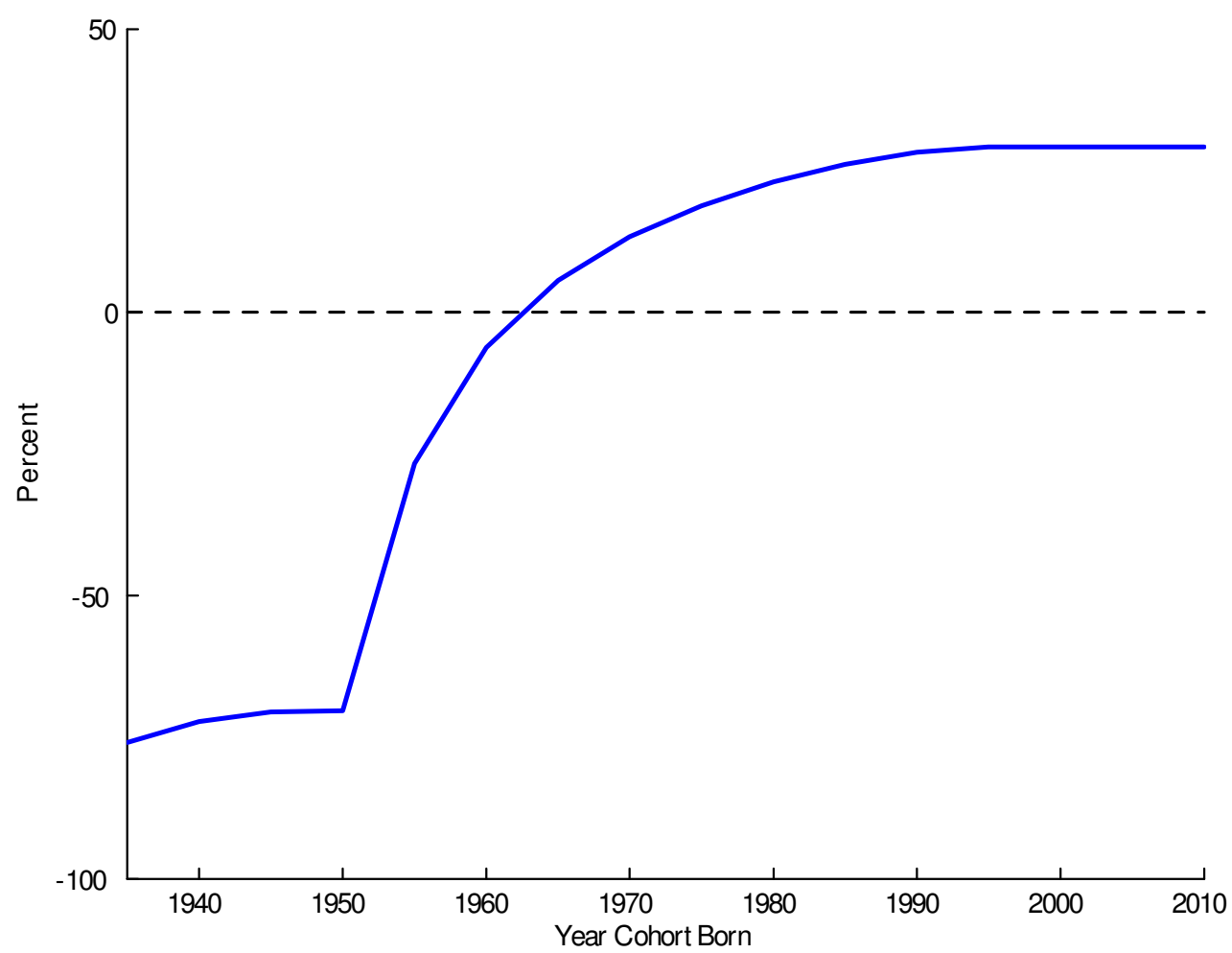

Note: GA are normalized by remaining life-time gross income 
Figure 2: Substituting Consumption for Labor Income Taxes Reform 1 (Closed Economy)
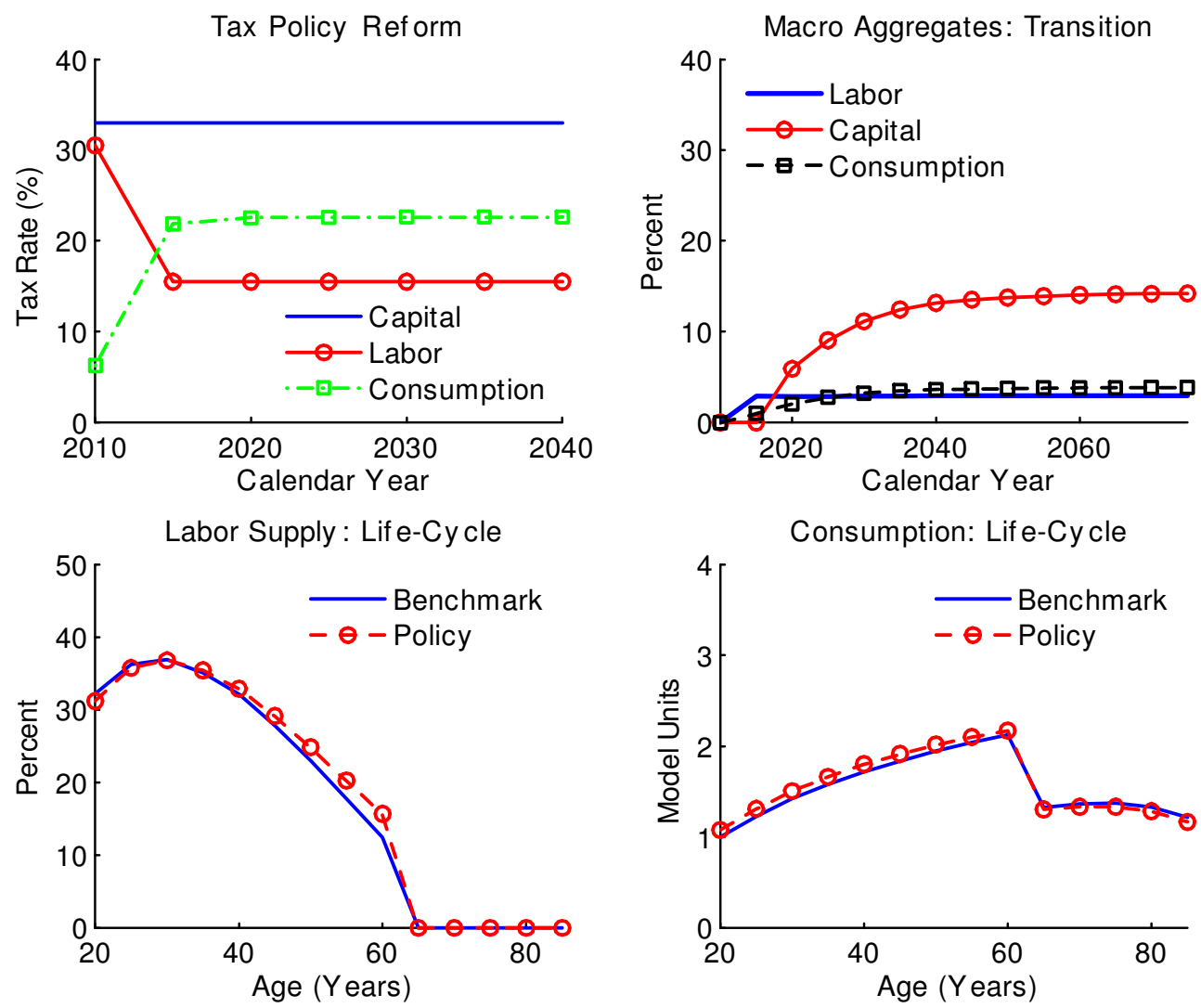
Figure 3: Generational Accounts and Welfare Reform 1 (Closed Economy)
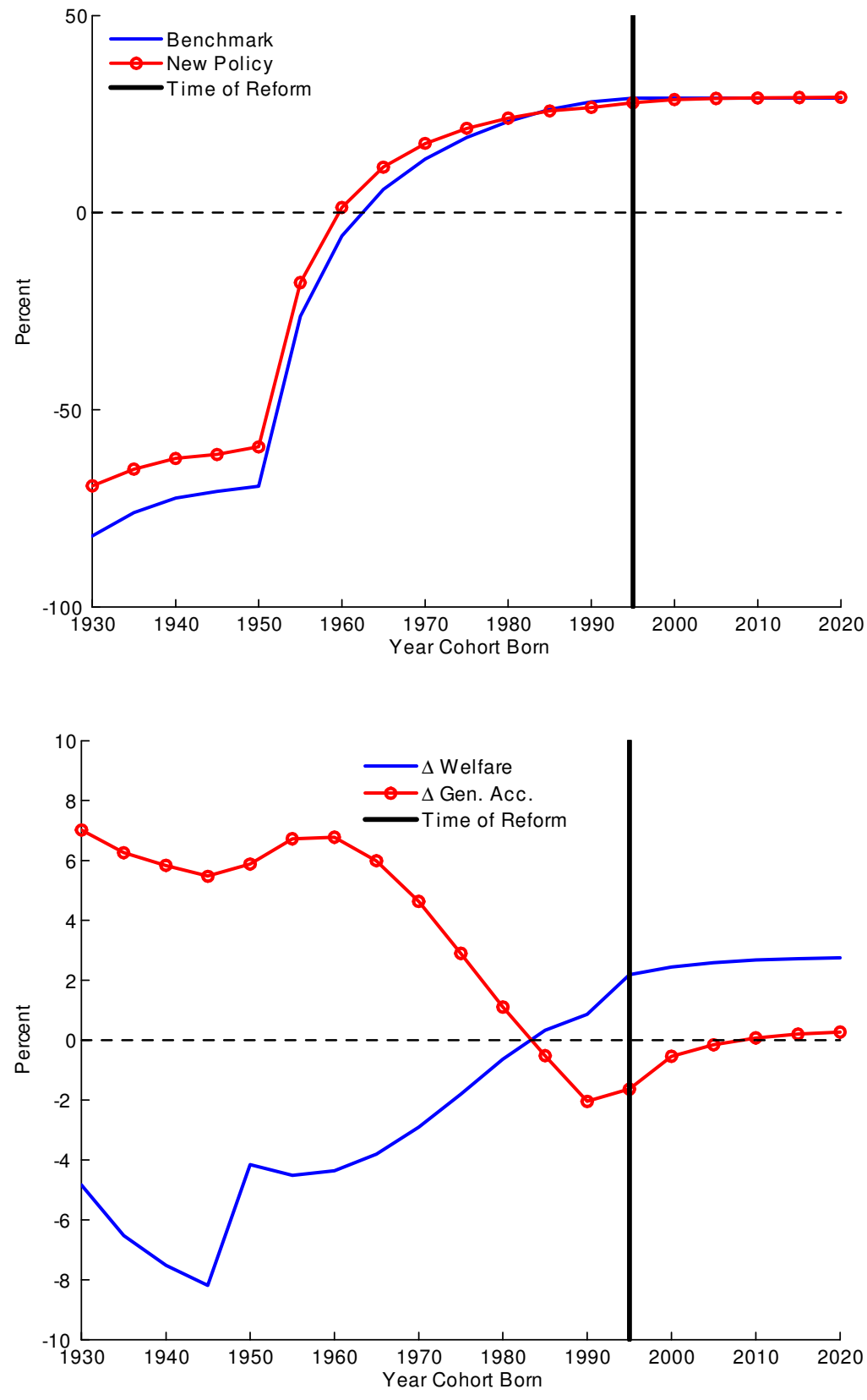

Note: $\triangle$ Welfare measured in equivalent variation, $\triangle$ Gen. Acc. normalized by lifetime net income benchmark 
Figure 4: Substituting Consumption for Labor Income Taxes Reform 1 (Open Economy)
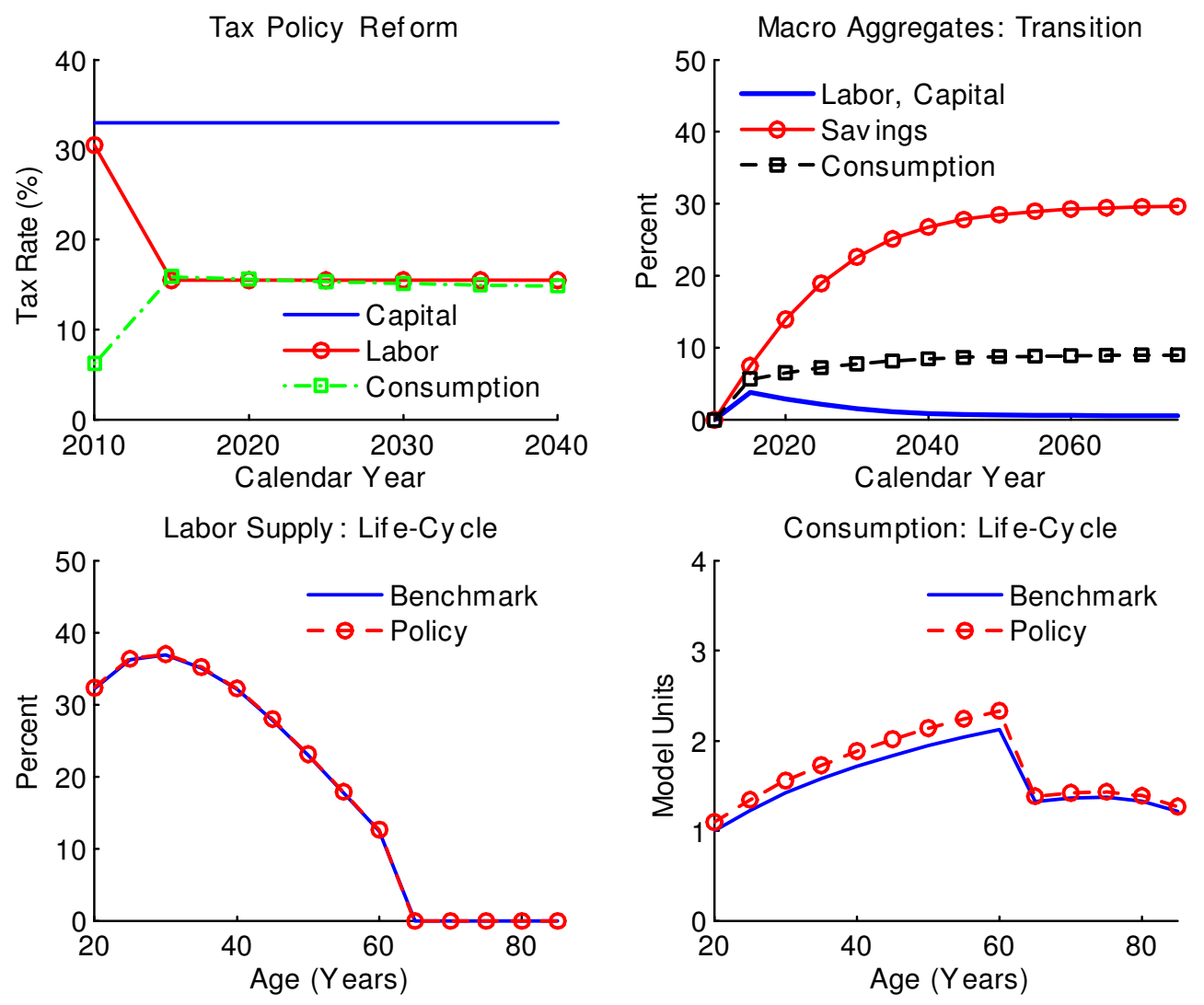
Figure 5: Generational Accounts and Welfare - Reform 1 (Open Economy)
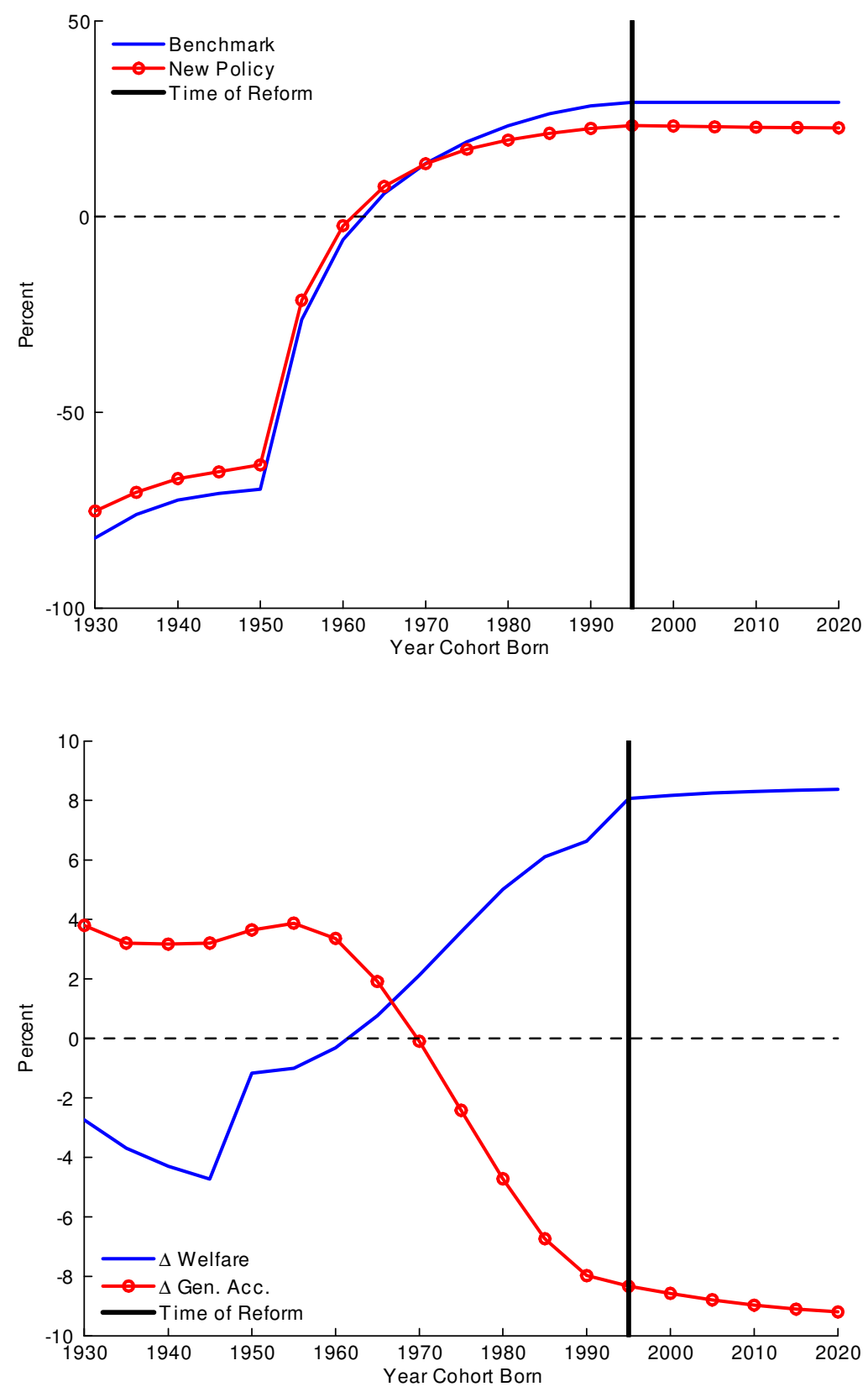

Note: $\triangle$ Welfare measured in equivalent variation,

$\triangle$ Gen. Acc. normalized by lifetime net income benchmark 


\section{Figure 6: Extension Retirement Age - Reform 2}
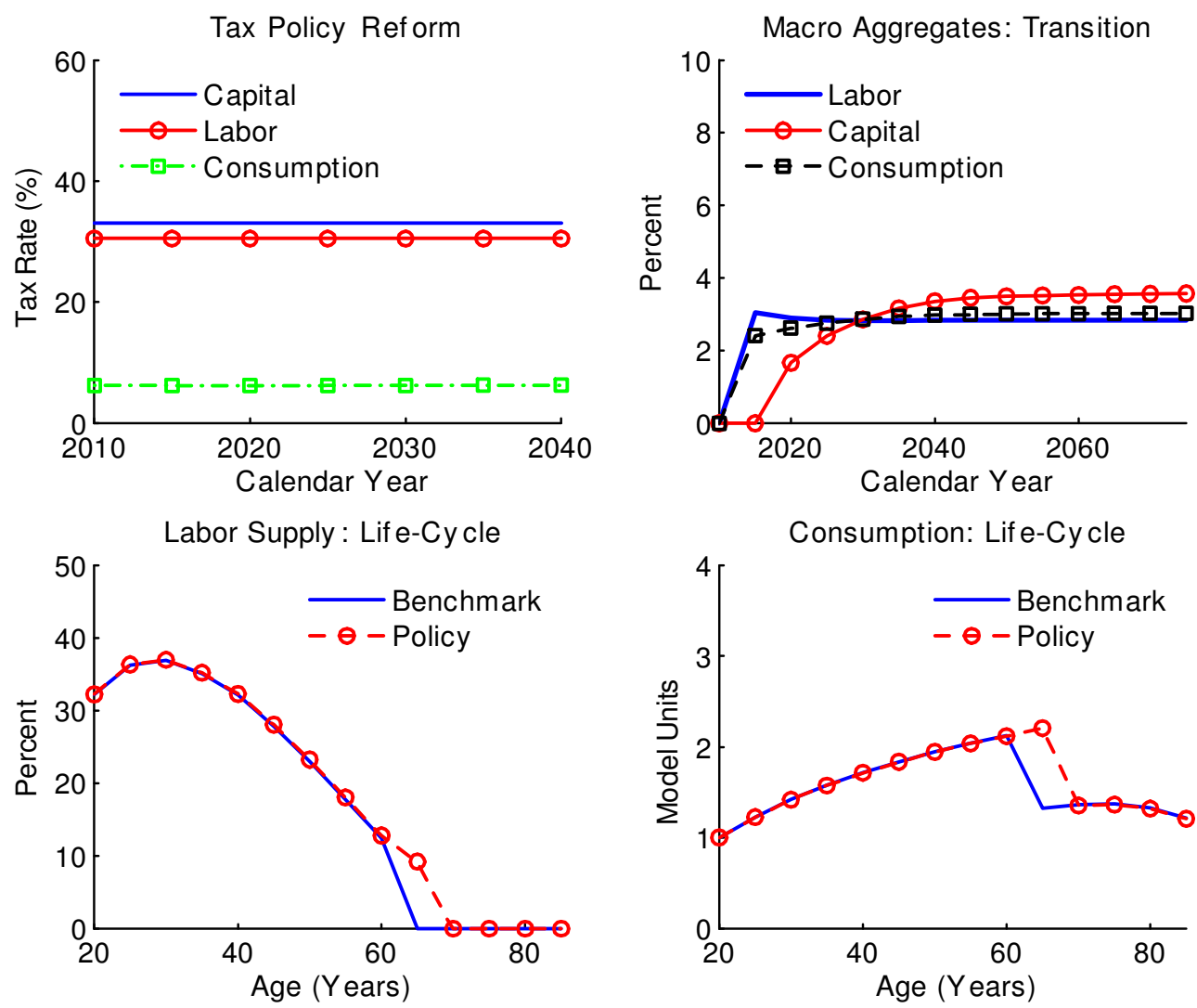
Figure 7: Generational Accounts and Welfare - Reform 2
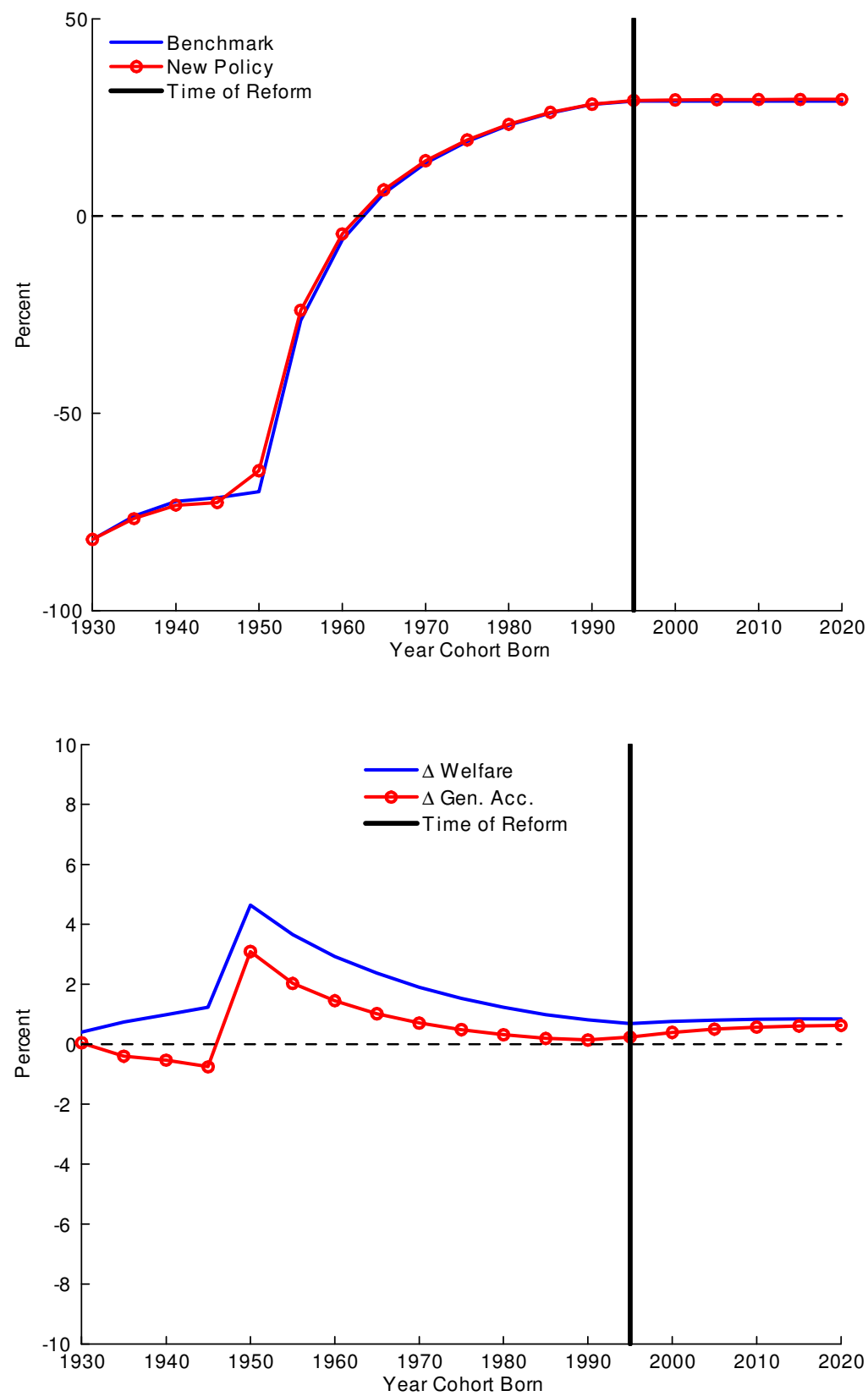

Note: $\triangle$ Welfare measured in equivalent variation,

$\triangle$ Gen. Acc. normalized by lifetime net income benchmark 
Figure 8: Generational Accounts and Welfare Optimal reform. Low Lambda $(\lambda=0.97)$
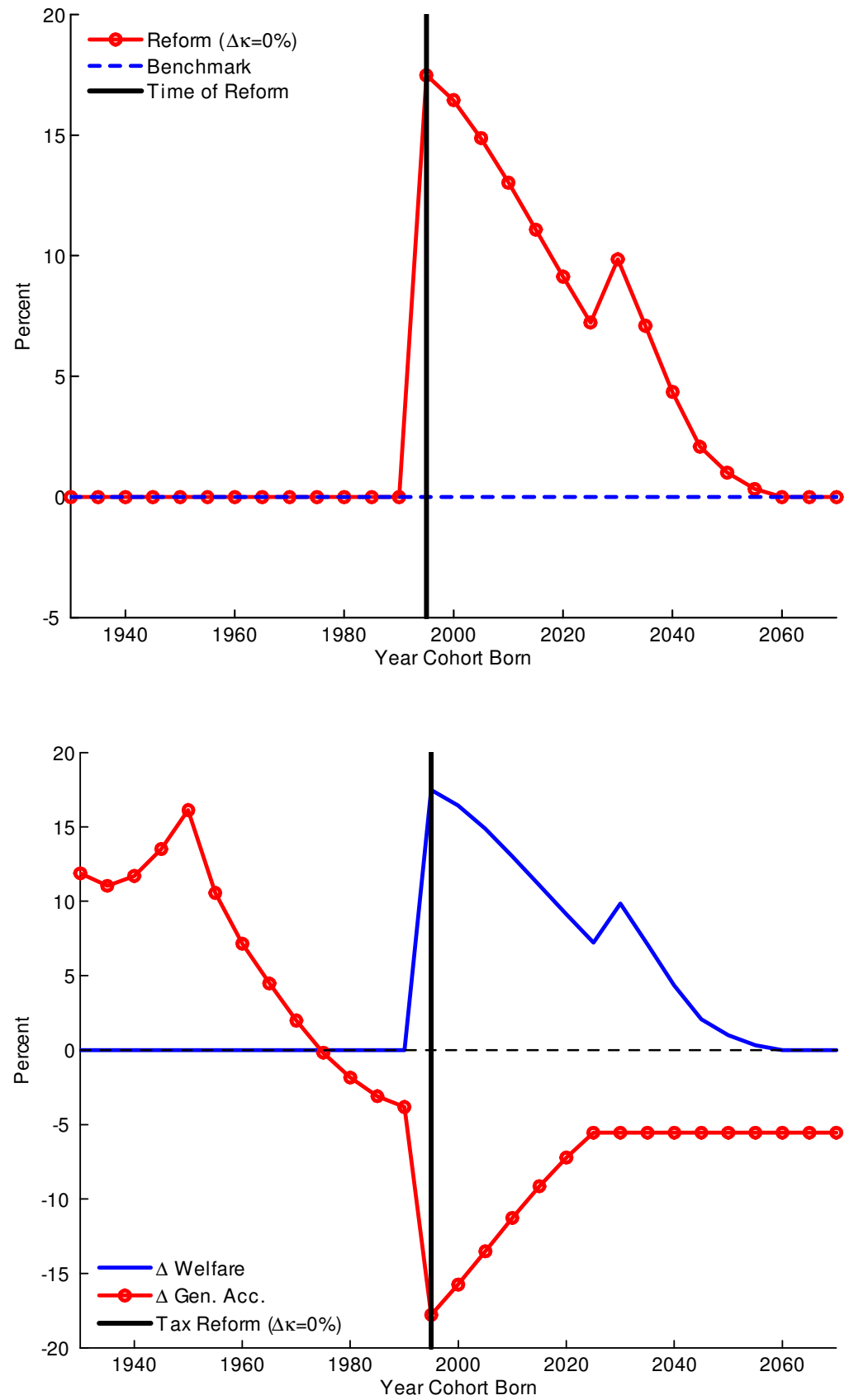

Note: $\triangle$ Welfare measured in equivalent variation,

$\triangle$ Gen. Acc. normalized by lifetime net income benchmark 


\section{Figure 9: Comparison Across Redistributive Reforms $(\triangle \kappa)$ Low Lambda $(\lambda=0.97)$}
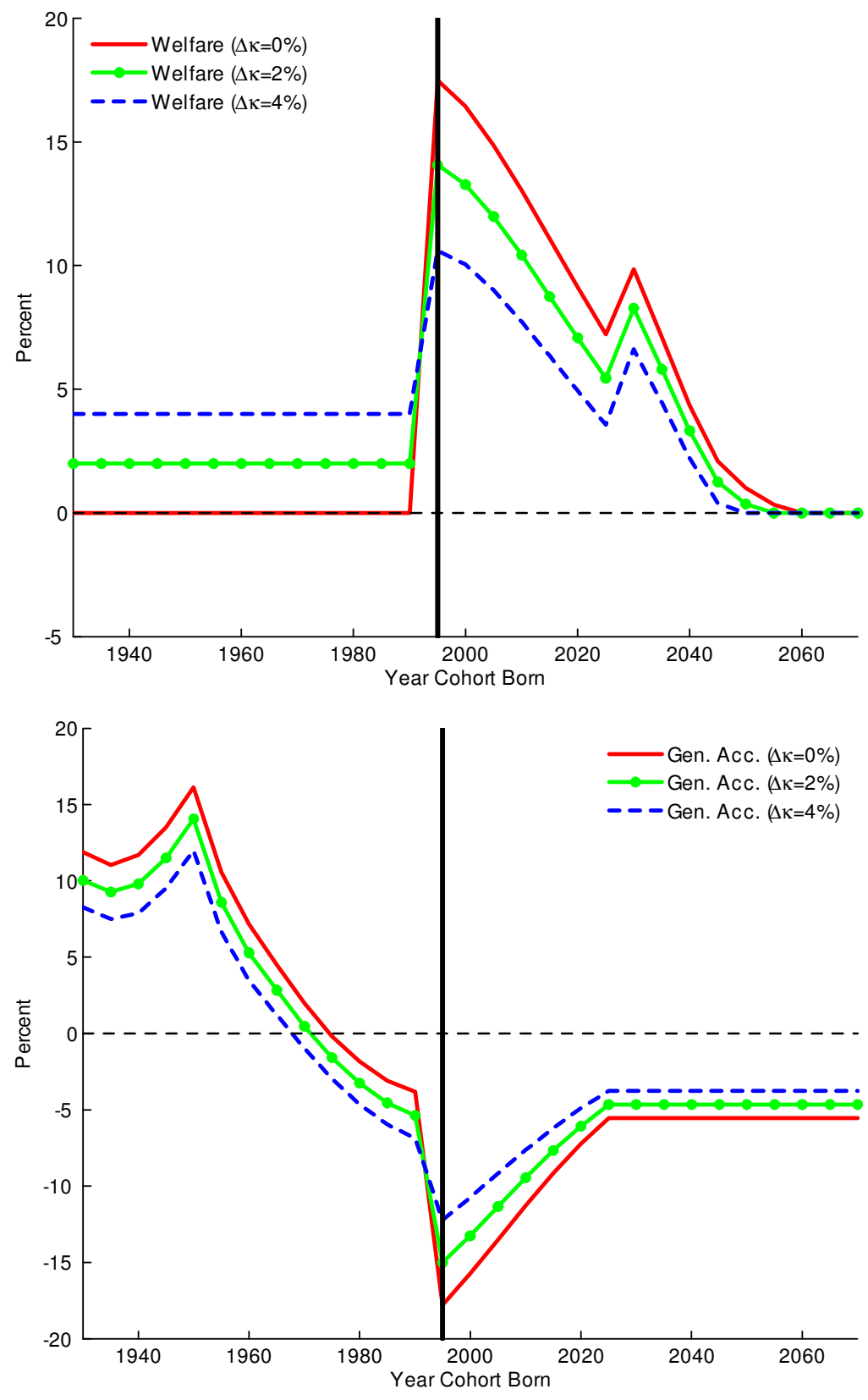

Note: $\triangle$ Welfare measured in equivalent variation, $\triangle$ Gen. Acc. normalized by lifetime net income benchmark 


\section{Figure 10: Optimal Consumption and Labor Supply. Low lambda}
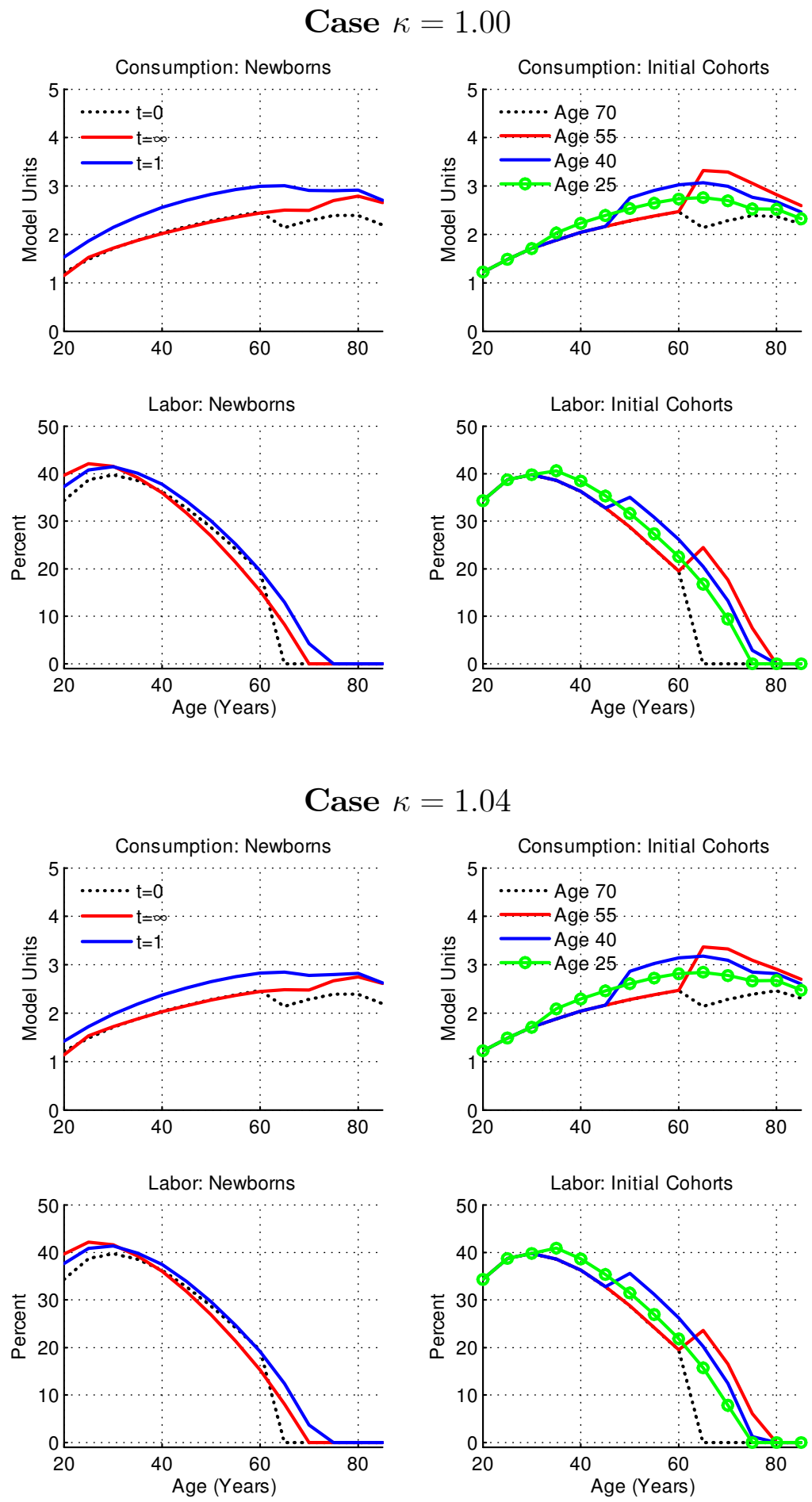
Figure 11: Generational Accounts and Welfare Optimal Reform. High Lambda $(\lambda=0.98)$
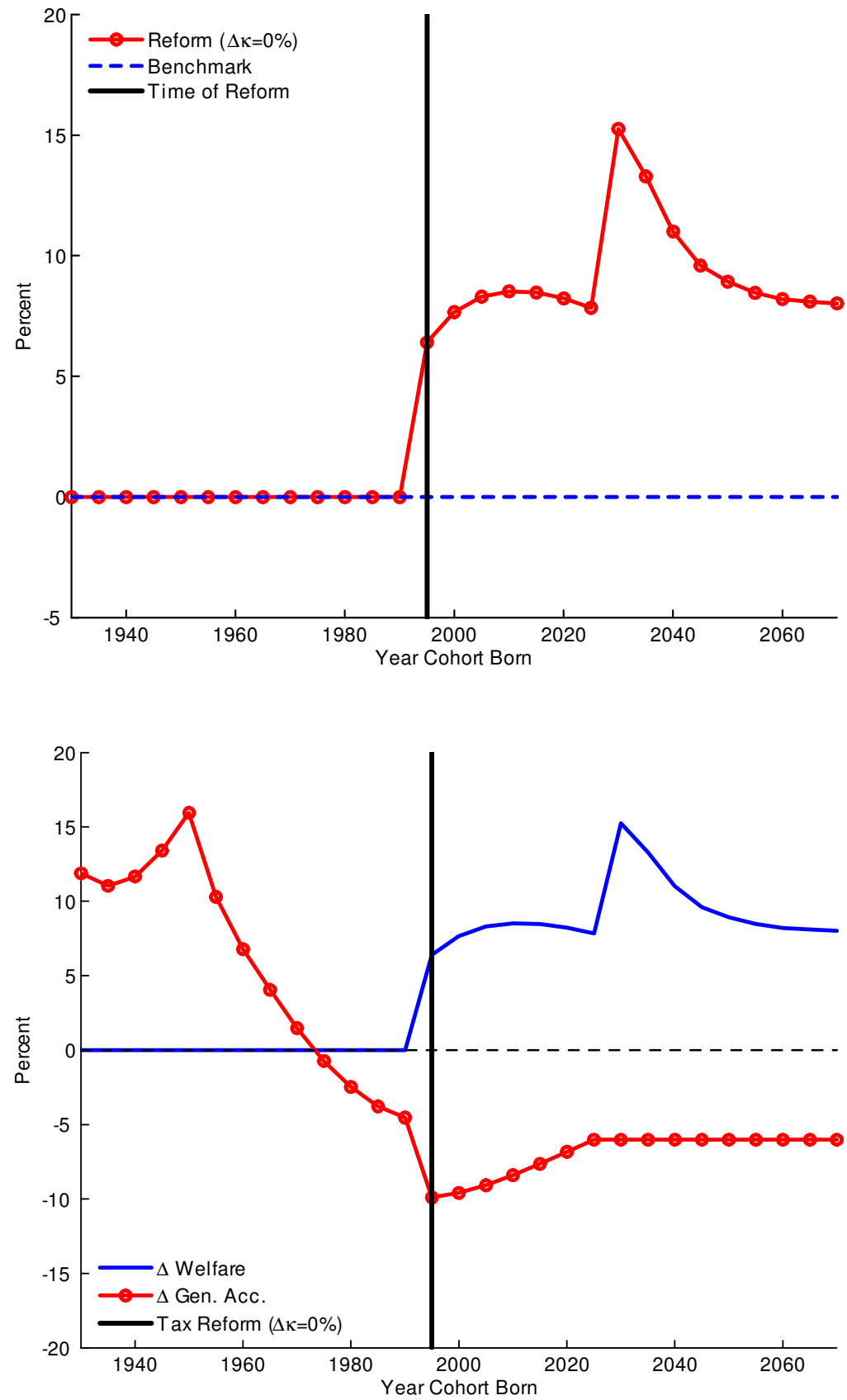

Note: $\triangle$ Welfare measured in equivalent variation,

$\triangle$ Gen. Acc. normalized by lifetime net income benchmark 
Figure 12: Comparison Across Redistributive Reforms $(\triangle \kappa)$ High Lambda $(\lambda=0.98)$
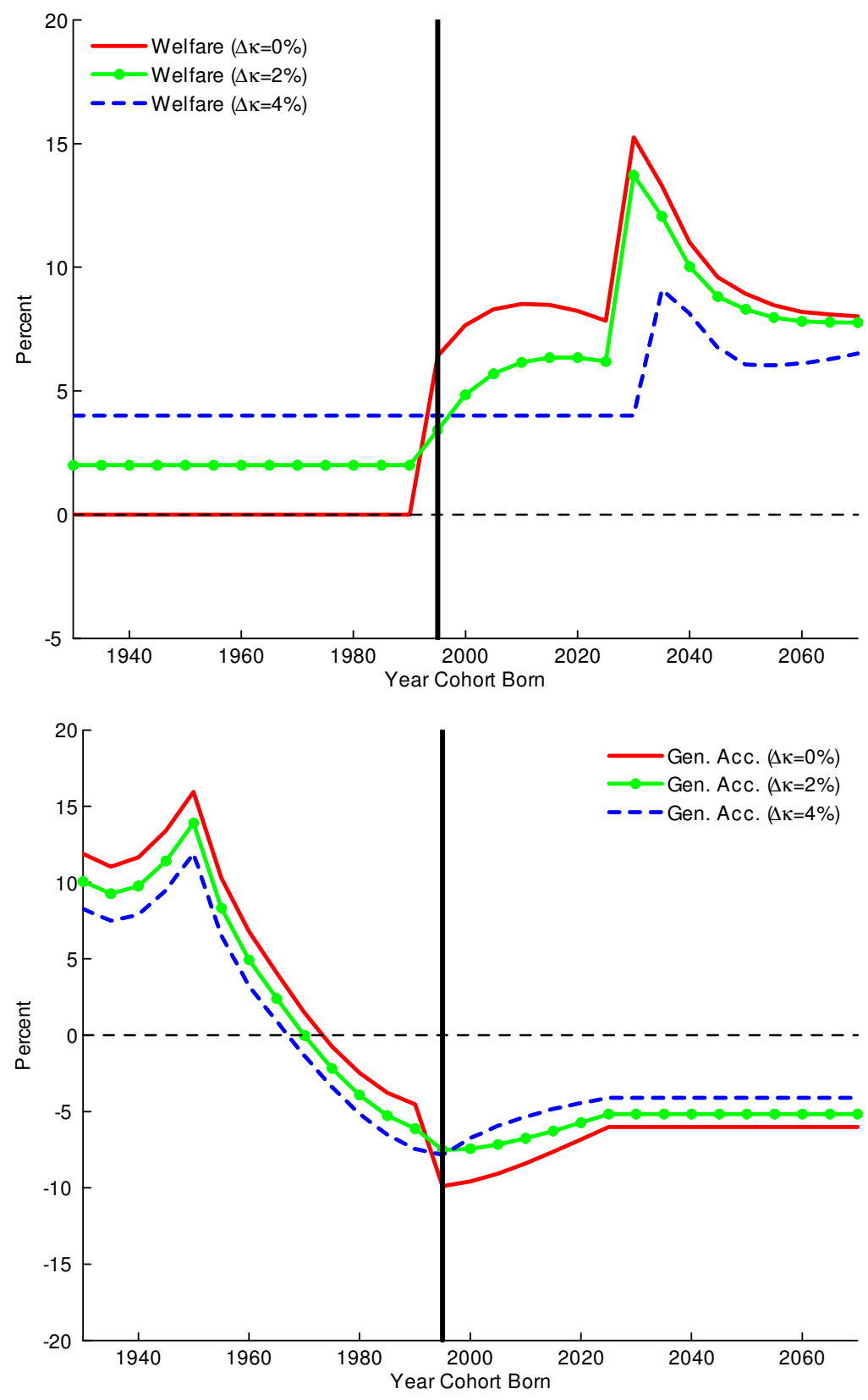

Note: $\triangle$ Welfare measured in equivalent variation, $\triangle$ Gen. Acc. normalized by lifetime net income benchmark 
Figure 13: Implications of Discounting for Aggregates
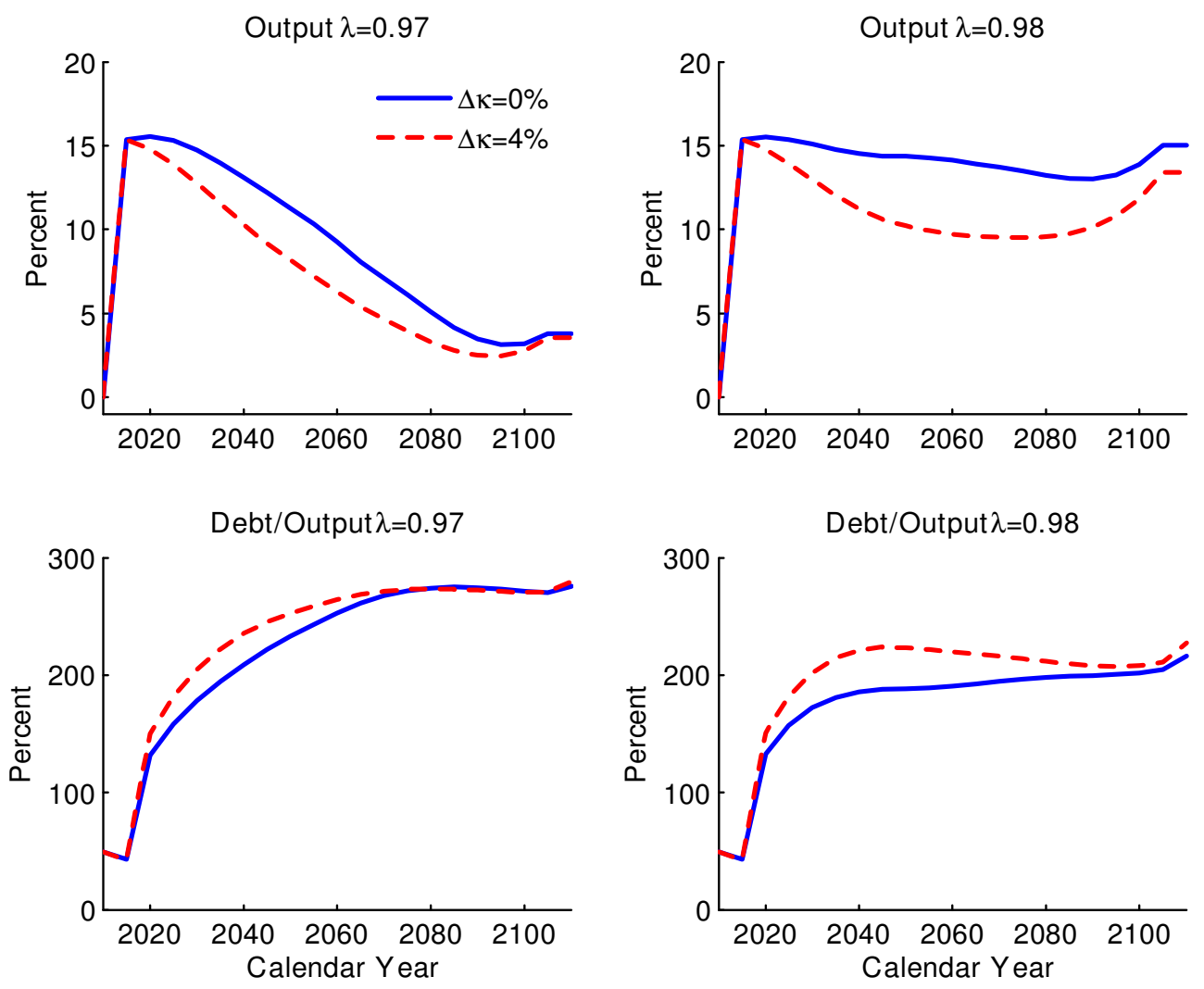
Figure 14: Optimal Policy (Age-Dependent Labor Taxes)
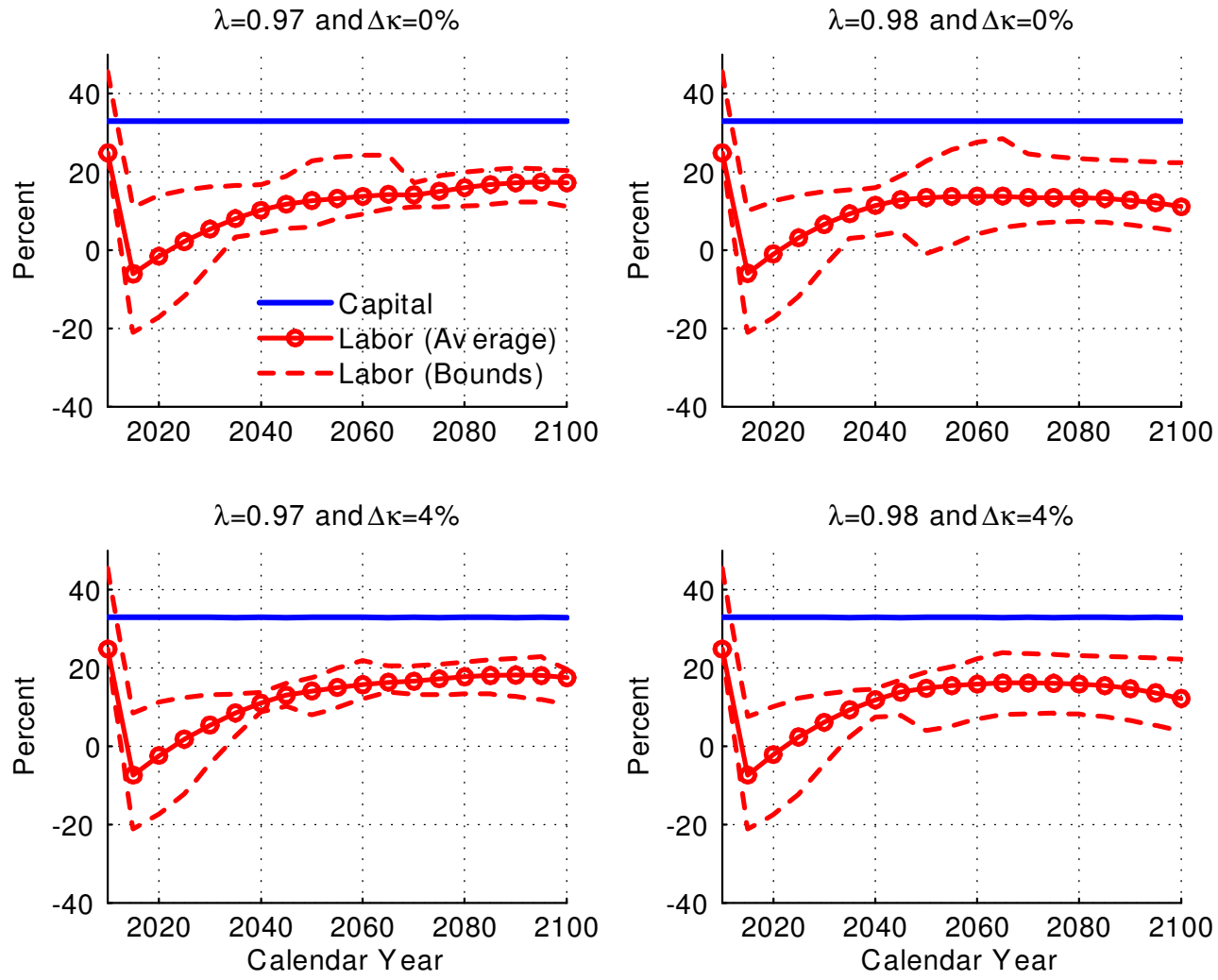